\title{
Amdyaz (aède, poète itinérant) (Maroc central)
} plur. : imdyazen ; fém. : tamdyazt = forme particulière de poésie du Maroc central.

\section{S. Chaker}

\section{OpenEdition}

\section{Journals}

\section{Édition électronique}

URL : http://journals.openedition.org/encyclopedieberbere/2469

DOI : 10.4000/encyclopedieberbere.2469

ISSN : 2262-7197

Éditeur

Peeters Publishers

\section{Édition imprimée}

Date de publication : 1 septembre 1986

Pagination : $576-577$

ISBN : 2-85744-282-3

ISSN : $1015-7344$

Référence électronique

S. Chaker, «Amdyaz (aède, poète itinérant) (Maroc central) », Encyclopédie berbère [En ligne], 4| 1986, document A187, mis en ligne le 01 décembre 2012, consulté le 12 octobre 2020. URL : http://

journals.openedition.org/encyclopedieberbere/2469; DOI : https://doi.org/10.4000/ encyclopedieberbere.2469

Ce document a été généré automatiquement le 12 octobre 2020.

(C) Tous droits réservés 


\section{Amdyaz (aède, poète itinérant) (Maroc central)}

plur. : imdyazen ; fém. : tamdyazt = forme particulière de poésie du Maroc central.

\section{S. Chaker}

1 Le terme appartient en propre aux parlers berbères du Maroc central (aire dialectale tamazixt) qui connaissent également la variante locale amlyaz. Le mot présente la forme d'un dérivé déverbatif (Nom d'Agent à préfixe $\mathrm{m}$-) construit sur une racine DYZ, laquelle, présentement, n'est plus attestée dans les parlers concernés. Il existe pourtant à Ghadames un verbe diz (< dyz), «danser» (Lanfry, p. 79, n 327) qui pourrait représenter la base de dérivation de amdyaz. Le rapprochement a été émis par A. Roux dès 1928. Cette hypothèse pourrait signifier que l'amdyaz a pu être primitivement membre (central) d'une troupe de danseurs, d'un ballet...

2 Les imdyazen représentent une forme semi-professionnelle de production et de diffusion de la poésie tamazixt. Le plus souvent, il s'agit de personnes qui n'exercent cette activité qu'une partie de l'année : leurs déplacements et leurs représentations ayant lieu entre la fin de l'hiver et le début de l'été. Ils consacrent le reste de l'année aux activités économiques habituelles de la région (élevages, agriculture). L'amdyaz traditionnel du Maroc central se distingue donc du

3 ays chleuh par un niveau de professionnalisation moins marqué et une plus grande intégration au tissu social dont il est plus immédiatement l'expression.

4 Arsène Roux a fournit dans son étude de 1928 une excellente et très complète description des imdyazen : le modèle type comporte le poète, (ampar $\mathrm{n}$ imdyazen $=$ «le chef des L), un joueur de flûte (bu- $ү a$ anim) et deux accompagnateurs (iredda-den = chroristes et tambourinaires) ;

- l'origine géographique des imdyazen, le plus souvent issus du Haut Atlas (tribus des Ayt Yafelman) ;

- Le processus de formation des imdyazen qui combine l'apprentissage «sur le tas » (participation à une troupe) et le recours à l'inspiration miraculeuse de certains saints protecteurs des poètes ; 
- Les déplacements des imdyazen qui couvrent l'ensemble de l'aire tamazixt, à l'exception des franges extrêmes du Nord-est (Ayt Warayn, Imermušen...), dont l'appartenance au groupe dialectal tamazixt a du reste été mise en doute par nombre de Berbérisants depuis bien longtemps (notamment Destaing, 1920).

- La langue poétique des imdyazen qui constitue, comme dans le domaine chleuh (Galand-Pernet, 1968 et 1972), une koiné littéraire. Volontiers archaïsante, elle puise, aux plans lexical et grammatical, dans l'ensemble des formes de l'aire dialectale ;

- Le déroulement des représentations et le répertoire des imdyazen.

5 Ce répertoire - en dehors d'intermèdes bouffons du bu-yanim - était et reste plutôt austère: édification religieuse, légendes hagiographiques (des grandes figures de l'Islam ou des saints et marabouts locaux), guerres (intertribales, lutte contre le Makhzen et les Français), événements et personnages locaux remarquables. Également le thé, l'amour et les femmes.

6 Un thème a connu un développement exceptionnel ces dernières décennies : celui des malheurs du temps présent (inversion des valeurs, perte de la foi et abandon des pratiques religieuses, pénétration des modes de consommation et des comportements occidentaux, individualisme...). La satire morale et sociale devient acerbe et renforce l'amdyaz dans son rôle traditionnel de juge, porte-parole et conscience du groupe rappelant à chacun les vraies valeurs de la société.

7 Tamdyazt, dans le vocabulaire spécialisé du Maroc central, désigne un genre particulier de poésie défini par J. Drouin (1975) comme :

8 "Un poème épique, religieux ou satirique de longueur variable, de vingt à quatrevingt-dix vers ou plus. La phrase rythmée est composée de vers de deux hémistiches assonances et non rimés dont le premier est chanté par le poète, amdyaz (...) et le second par un ou plusieurs imdyazen » (p. 159).

amdyaz/imdyazen et tamdyazt ont été introduits depuis une dizaine d'années dans l'usage kabyle avec les significations générales de " poète » et " poésie ».

\section{BIBLIOGRAPHIE}

Destaing E. Étude sur le dialecte berbère des Aït-Seghrouchen (Moyen Atlas marocain), Paris, Leroux, 1920.

Drouin J. Un cycle hagiographique dans le Moyen Atlas marocain, Paris, Publications de la Sorbonne, imprimerie nationale, 1975, p. 158 et sq.

Galand-Pernet P. «A propos d'une langue littéraire berbère au Maroc », Verhandlungen des zweiten internationalen Dialektologenkongresses, Wiesbaden, 1968, p. 260-267.

Galand-Pernet P. Recueil de poèmes chleuh..., Paris, Klincksieck, 1972, (cf. introduction).

Lanfry J. Ghadames, II (glossaire), Alger, F.B.D., 1970.

Roux A. « Les "imdyazen" ou aèdes berbères du groupe linguistique beraber ", Hespéris, 1928, 2e trimestre. 
INDEX

Mots-clés : Littérature orale, Maroc, Sociologie 